\title{
EUCLIDES DA CUNHA E A RODOVIA TRANSAMAZÔNICA.
}

\section{GERALDO JOFFILY \\ Brasília.}

A construção da rodovia transamazônica vem despertando as atenções de todo o Pais e constitui, sem dúvida, um empreendimento que modificará o panorama político e econômico do Brasil.

$\mathrm{Na}$ verdade, a Amazônia tem permanecido, até hoje, como uma região praticamente inexplorada, porque nossas possibilidades tecnológicas não permitiam desbravar aquela imensa área; coberta pela maior floresta do mundo. Só agora temos condiçōes para a realização desta obra, mas a idéia vem de longe e seria proveitoso recordar alguns planos de Euclides da Cunha sobre a integração da Amazônia, isso há mais de 65 anos, pois foi ele quem melhor viu o conjunto de problemas e interesses direta ou indiretamente ligados à Hiléa Amazônica.

Neste sentido ajuntamos os principais tópicos de Euclides da Cunha, referentes a integração da Amazônia, com o objetivo de facilitar uma maior percepção do pensamento euclidiano e a perfeita semethança de suas agudas previsões com os atuais planejamentos para execução $\mathfrak{e}$ aproveitamento da grande rodovia, que já vai penetrando na imensa floresta virgem.

Desde Os Sertões apega-se Euclides da Cunha à questão básica da integração nacional, que se tornaria uma constante em todos os seus estudos e verificações:

"O velho agregado colonial tendia a chegar ao nosso tempo, imutavel, sob o emperramento de uma centralização estúpida" (1). "Vivemos quatrocentós anos no litoral vastíssimo, deixando, na penumbra em que jaz, o ámago do País" (2). "O Brasil é com-

(1). - Euclides da Cunha, Os Sertóes, p. 81 da 3a. ediçắo.

(2). - Ibidem, p. 205. 
pacto. Falta-lhe penetrabilidade" (3). "Não desejo a Europa (continua ele), desejo o sertão, a picada malgradađa... A partida para o Purús é ainda o meu mais belo e arrojado ideal. Estou presente à primeira voz..." (4). "Para vingar a Hiléa de todas as brutalidades das gentes adoidadas que a maculam desde o século dezassete" (5).

"O Amazonas é uma esperança, deixando as visinhanças do Pará penetra-se no deserto" (6). "A Amazônia é, de toda a América, a paragem mais perlustrada dos sábios e é a menos conhecida. De Humboldt a Goeld, do alvorar do século passado aos nossos dias... Nenhum deles deixou a calha principal" (7).

No relatório sobre a Comissão Demarcatória, que chefiou, no alto Purús, Euclides da Cunha pôs o dedo na ferida para mostrar os efeitos do isolamento:

"O homem, em vez de senhorear a terra escravisa-se aos rios. O povoamento não se expande ... A propriedade mal distribuida, ao passo que se dilata nos latinfúndios das terras, que só se limitam de um lado pelas beiradas do rio, reduz-se econômicamente nas mãos de um número restrito de possuidores. O rude seringueiro é duramente explorado, vivendo despeado do pedaço de terra em que pisa longos anos, exigindo urgentes providências que the garantam melhores resultados a tão grandes esforços. E um quase servo, à mercê do império discricionário dos patrôes. A justiça é, naturalmente, seródia ou nula. Todos esses males provem, acima de tudo, do fato meramente físico da distância. Desaparecerão, desde que se incorpore a sociedade sequestrada ao resto do país" (8).

No combate ao isolamento, todos os esforços, mesmo empíricos, merecem as atenções de Euclides da Cunha. Vê a utilidade prática da picada,

\footnotetext{
"varadouro, como chamam a vereda atalhadora que vai de uma vertente fluvial à outra"
}

(3). - Euclides da Cunha, Contrastes e Confrontos, (Ao longo de uma estrada, 2a. parte)

(4) . Euclides da Cunha, Carta a José Veríssimo, (Francisco Venâncio Filho, Euclides da Cunha a seus amigos).

(5). - Ob. cit. (Carta a Coelho Neto).

(6) - Euclides da Cunha, citando Tavares Bastos, Contrastes e Confrontos. (Entre o Madeira e o Javary, início). nas, 2a. parte)

(7). - Euclides da Cunha, $\dot{A}$ Margem da História. (Diante do Amazo-

(8). - Euclides da Cunha, Antologia. (Relatórios). 
e lembra a construção de uma estrada de ferro, muito embora precaríssima, cortando as cabeceiras dos rios Juruá, Tarauacá, Purús, Iaco e Acre:

"A estrada crescerá com o povoamento (continua Euclides). $E$ ainda que atinja àquele enorme desdobramento de $726 \mathrm{kms}$ e se reduza a uma via síngela, com os necessários desvios, comportando apenas uma velocidade de $20 \mathrm{kms}$ por hora, será percorrida em 36 horas, que podem subir a 48 , adiantando-se-lhes as que empregam na travessia dos rios. Realizar-se-á em dois dias a viagem de Cruzeiro do Sul ao Acre (Capital), que hoje, nas quadras mais apropriadas, dura mais de mês... E assim, desde que se ultime a Madeira-Mamoré... a Transacreana, modestíssima, de carater local, se transformará em estrada de extraordinários destinos" (9).

Esta notavel previsão acaba de ser relembrada por Leandro Tocantins:

"Nesta simples penada, Euclides da Cunha, através de uma surpreendente geografia de comunicações, discortinou horizontes novos para o seu modesto projeto inicial, lançando as bases de um traçado rodoviário em realização, ou $\mathrm{cm}$ cogitação, nos dias de hoje. A rodovia Brasília-Acre, aberta pioneiramente, acompanha a direção prevista pelo autor de $\dot{A}$ Margem da História, e o picadão que existe entre Rio Branco e o Juruá, prenuncia a próxima transacreana, destinada, conforme a predição euclidiana, a Transformar-se na rodovia Pan-Americana, que ligará o Canadá à República Argentina. Confirma-se, portanto, a atilada visão de Euclides": "O que se deve ver naquela via-férrea é, sobretudo, uma grande estrada internacional de aliança civilizadora e de paz" (10).

Euclides da Cunha via no problema das estradas brasileiras de penetração, não apenas o aspecto nacional, mas tambem os seus efeitos nos paises vizinhos:

"Nenhuma de nossas redes busca o centro do País, visando despertar as energias que o afastamento do litoral amortece... Felizmente (diz Euclides) a Estrada de Ferro do Noroeste, lan-

\footnotetext{
(9). - lbidem.

(10). - Leandro Tocantins, Euclides da Cunha e o Paraiso Perdido, p. 103 .
} 
çada vigorosamente para Mato Grosso (1906) revolucionará muito breve tôda situação econômica e política da América do Sul" (11).

Na verdade, esta operação só principiaria a objetivar-se mais de meio século depois.

"O Pacífico (continua Euclides) ainda que se rasgue o canal de Nicaragua (Panamá) parece que pouco influenciará no progresso do Perú. O seu verdadeiro mar é o Atlântico, a sua saida obrigatória o Purús. Desde 1879 os peruanos aquilatam bem a importância enorme que teriam as estradas, ligando os afluentes navegáveis do Amazonas e do Ucaiale às cidades do litoral" (12).

E interessante notar, como Euclides da Cunha apresenta o mesmo problema, invertendo os polos da questão, para salientar

"a importância formidavel desta estrada (Estrada de Ferro do Noroeste), que vai aproximar-nos do Pacífico, seguindo, paralelamente, o próprio deslocamento da civilizaçăo" (13).

Essas glebas imensas, sem efetiva integração, correm o sério risco de uma rutura política e territorial. O gravíssimo problema, como decorrência do isolamento, é igualmente apontado por Euclides da Cunha:

"As novas circunscriçōes do alto Purús, do alto Juruá e do Acre devem refletir a ação persistente do Govêrno em um trabatho de incorporação, que, na ordem prática, exige desde já a facilidade das comunicações e a aliança das idéias. Sem este objetivo firme e permanente, aquela Amazônia, onde mais cedo ou mais tarde (continua Euclides) se destacará do Brasil, naturalmente, e irresistivelmente, como se despega um mundo de sua nebulosa, pela expanção centrífuga do seu próprio movimento" (14). "Na pressão atual da vida contemporânea, a expansão irresistivel das nacionalidades deriva-se, como a de todas as forças naturais, segundo as linhas de menor resistência" (15).

Euclides da Cunha viveu numa época em que as estradas de ferro representavam a melhor solução para os transportes continentais, mas, desde o seu início, apercebeu-se do valor das estradas de roda-

(11). - Euclides da Cunha, $A$ Margem da História. (Ferrovia e desenvolvimento).

(12) . - Euclides da Cunha, Contrastes e Confrontos. (Conflito inevitavel $\mathrm{n}^{9}$ III).

(13). - Ibidem. (Ao longo de uma estrada $\mathrm{n}^{9}$ III, nota 1).

(14). - Ibidem. (Entre o Madeira e o Javary, final).

(15). - Ibidem. (Ideal americano). 
gem. Desde 1906, quando a indústria automobilista ainda era um requinte, salientava Euclides da Cunha:

"Uma estrada de rodagem para Mato Grosso, digna de tal nome, principalmente agora que o automobilismo libertou a velocidade do trilho, não seria apenas o melhor meio de nos emanciparmos do Prata, nesta fase incandescente da política sulamericana, mas ainda, sob aspecto mais real, um belo laço de solidariedade, revigorando uma integração já consideravelmente comprometida" (16). "E a tarefa é relativamente facil. Temos um termo de comparação expressivo na única estrada de rodagem de todo o Brasil, a da - União Indústria -, desenvolvida de Juiz de Fora a Petrópolis, com um percurso de $147 \mathrm{kms}$, macadamizada, que outrora faria inveja as melhores ruas de nossas capitais. Surgiu da vontade de ferro de um Mariano Procópio e foi executada em condiçōes desfavoráveis. Mas foi feita, larga de oito metros. Ora, uma estrada idênticamente modelada para Mato Grosso, seria apenas oito vezes e meia maior" (17).

Muitos destes conceitos, analisados por Euclides da Cunha há mais de 65 anos, ainda são atualíssimos, justificando e empenho prioritário que vem merecendo a construção das nossas estradas de penetração, sem esquecer a delicada elaboração de normas e leis complementares, de cuja observância tanto depende o exito da gigantesca obra de integração nacional.

(16). - Ibidem. (Ao longo de uma estrada, 2a. parte).

(17). - Ibidem. (3a. parte). 